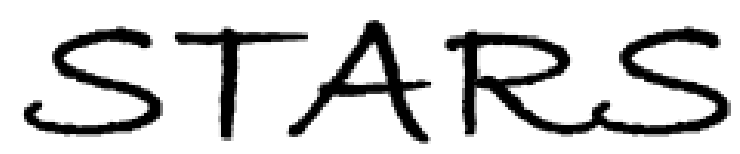

University of Central Florida

STARS

Faculty Bibliography 2010s

Faculty Bibliography

$1-1-2013$

\title{
Attending Physicians on Ward Rounds
}

Robert M. Centor

Analia Castiglioni

University of Central Florida

Brita Roy

Find similar works at: https://stars.library.ucf.edu/facultybib2010

University of Central Florida Libraries http://library.ucf.edu

This Letter is brought to you for free and open access by the Faculty Bibliography at STARS. It has been accepted for inclusion in Faculty Bibliography 2010 s by an authorized administrator of STARS. For more information, please contactSTARS@ucf.edu.

\section{Recommended Citation}

Centor, Robert M.; Castiglioni, Analia; and Roy, Brita, "Attending Physicians on Ward Rounds" (2013).

Faculty Bibliography 2010s. 3770.

https://stars.library.ucf.edu/facultybib2010/3770

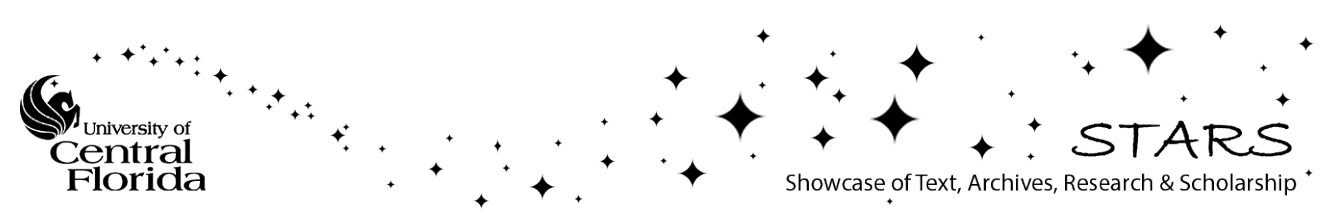




\section{Attending Physicians on Ward Rounds}

To the Editor: Drs Wachter and Verghese ${ }^{1}$ considered the complexity of ward attending rounds in the current health care environment in a Viewpoint. We examined ward attending rounds $\mathrm{s}^{2,3}$ using consumer preference techniques to learn how students, residents, and attending physicians view rounds. Our results complement and expand the observations in the Viewpoint.

We learned that successful attending rounds required a multidimensional skill set comprised of 5 distinct domains: learning atmosphere, clinical teaching, teaching style, communicating expectations, and team management. As Wachter and Verghese explained, current work hour restrictions and hospital expectations create a demand for team management skills, one of our domains. This domain includes timeliness, efficiency, and accommodating absences required for administrative demands.

While team management is an important domain, it did not outweigh clinical teaching, learning atmosphere, teaching style, or communicating expectations. Trainees valued teaching. They rated "sharing of attending's thought processes" as the top attribute for successful rounds. They also valued bedside teaching and role modeling. These less precise attributes of clinical wisdom trumped the teaching of evidence-based literature. Students and residents felt they could read books and medical literature, but they wanted and needed attending physicians to demonstrate clinical reasoning, patient communication, physical examination skills, and professional physician behavior.

Our studies also suggest the balance between teaching and efficiency is directly dependent on the daily workload. While trainees usually valued clinical teaching (including demonstrating clinical reasoning and physical examination skills on days with a high patient census), efficiency superseded teaching. Thus, attending physicians ought to be flexible and adjust their rounding style according to the team's needs.

Regardless of age, specialty, and institution, students and residents deserve attending physicians who demonstrate physician excellence and can explain what they are doing and why they are doing it. As Wachter and Verghese asserted, the attending role is complex and therefore requires deliberate training to improve. We have begun holding faculty development sessions in which we focus on the key issues our research identified.

Robert M. Centor, MD

Analia Castiglioni, MD

Brita Roy, MD, MPH

Author Affiliations: University of Alabama, Birmingham (Drs Centor and Roy) (rcentor @uab.edu); and University of Central Florida, Orlando (Dr Castiglioni).

Conflict of Interest Disclosures: The authors have completed and submitted the ICMJE Form for Disclosure of Potential Conflicts of Interest and none were reported.
1. Wachter RM, Verghese $A$. The attending physician on the wards: finding a new homeostasis. JAMA. 2012;308(10):977-978.

2. Castiglioni A, Shewchuk RM, Willett LL, Heudebert GR, Centor RM. A pilot study using nominal group technique to assess residents' perceptions of successful attending rounds. J Gen Intern Med. 2008;23(7):1060-1065.

3. Roy B, Castiglioni A, Kraemer RR, et al. Using cognitive mapping to define key domains for successful attending rounds. J Gen Intern Med. 2012;27(11):14921498.

In Reply: It is interesting-and reassuring-that trainees appear to value hearing their attending physician's thought processes more than a recitation of evidencebased literature. The ubiquitous availability of online resources has had the effect of turning clinical evidence into a commodity, which is a good thing. Wisdom and experience are harder to commoditize, and attending physicians are uniquely positioned to offer them to their trainees.

Like Dr Centor and colleagues, we believe that effective faculty development programs can allow junior attending physicians to traverse their learning curves more rapidly. Junior faculty may be less comfortable "thinking out loud" and more inclined to equate teaching with discussing the results of the latest literature. Providing such faculty with the tools to teach more effectively, and to appreciate the value of sharing their clinical wisdom, should be a high priority. On the other hand, Centor and colleagues' findings should not be taken as license by senior faculty to not keep up with the literature. The attending physician's thought process must be based on a foundation of an up-to-date understanding of the literature.

Unfortunately, the tension between efficiency and teaching is likely to get even harder to balance in the next few years, driven by the troubling economics of health care. It will be a cruel irony if, just as faculty come to appreciate their roles in teaching trainees to deliver highvalue, cost-conscious care, the time needed to deliver this content is no longer available because of economic imperatives.

Robert M. Wachter, MD

Abraham C. Verghese, MD

Author Affiliations: University of California, San Francisco (Dr Wachter); and Stanford University, Palo Alto, California (Dr Verghese; abrahamv@stanford.edu). Conflict of Interest Disclosures: The authors have completed and submitted the ICMJE Form for Disclosure of Potential Conflicts of Interest. Dr Wachter reported serving as the chair of the American Board of Internal Medicine (for which he receives a stipend); receiving a grant to his institution from the Agency for Healthcare Research and Quality; receiving honoraria from more than 100 health care organizations for lectures on patient safety, heath care quality, and hospitalists; receiving royalties from Lippincott Williams \& Wilkins and McGraw-Hill; receiving fees for development of educational presentations from QuantiaMD and IPC: The Hospitalist Company; serving on the scientific advisory boards of PatientSafe Solutions, EarlySense, and CRISI (for which he receives stock options); receiving compensation from John Wiley \& Sons for blog writing; holding the Benioff endowed chair in hospital medicine from Marc and Lynne Benioff; and receiving funding for sabbatical at Imperial College from the US-UK Fulbright Commission. Dr Verghese reported serving on the speakers bureaus of and receiving royalties from Knopf and Random House and from foreign publishers for translations of his work; receiving honoraria from health care, universities, and literary societies for lectures related to his books and related to medicine; and reported that some of his work is funded by an unrestricted grant to his institution from Pfizer earmarked for continuing medical education tools for physicians. 